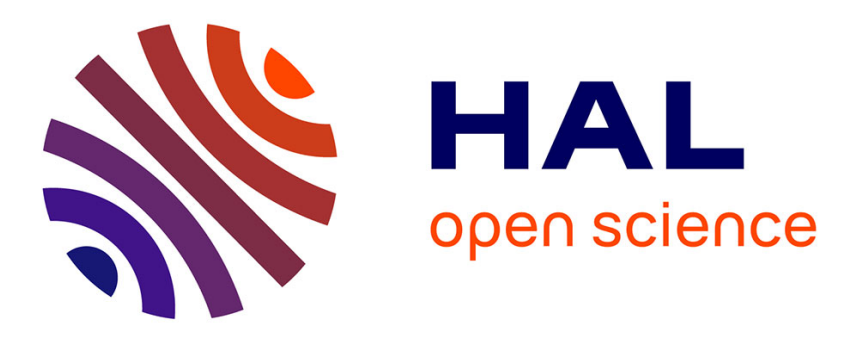

\title{
Online training on how to diagnose anoperineal lesions of Crohn's disease: Do pictures matter? A nationwide randomized study
}

C. Geffrier, V. de Parades, L. Abramowitz, P. Benfredj, G. Bonnaud, C. Bord, D. Bouchard, G. Bouguen, F. Devulder, Jm. Didelot, et al.

\section{To cite this version:}

C. Geffrier, V. de Parades, L. Abramowitz, P. Benfredj, G. Bonnaud, et al.. Online training on how to diagnose anoperineal lesions of Crohn's disease: Do pictures matter? A nationwide randomized study. Clinics and Research in Hepatology and Gastroenterology, 2019, 43, pp.483 - 496. 10.1016/j.clinre.2018.12.003 . hal-03487431

\section{HAL Id: hal-03487431 \\ https://hal.science/hal-03487431}

Submitted on 20 Dec 2021

HAL is a multi-disciplinary open access archive for the deposit and dissemination of scientific research documents, whether they are published or not. The documents may come from teaching and research institutions in France or abroad, or from public or private research centers.
L'archive ouverte pluridisciplinaire HAL, est destinée au dépôt et à la diffusion de documents scientifiques de niveau recherche, publiés ou non, émanant des établissements d'enseignement et de recherche français ou étrangers, des laboratoires publics ou privés.

\section{(ㄷ)(1) $\$$}

Distributed under a Creative Commons Attribution - NonCommerciall 4.0 International 


\section{Online training on how to diagnose anoperineal lesions of Crohn's disease: do pictures matter? A nationwide randomized study}

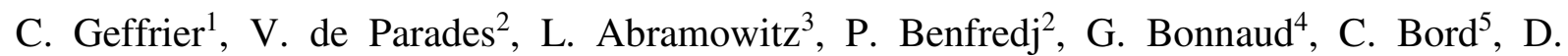
Bouchard $^{6}$, G. Bouguen ${ }^{7}$, F. Devulder ${ }^{8}$, JM. Didelot ${ }^{9}$, N. Fathallah ${ }^{2}$, T. Higuero ${ }^{10}$, X. Lesage $^{11}$, A. Nouts ${ }^{12}$, P. Petit ${ }^{13}$, F. Pigot ${ }^{4}$, E. Pommaret ${ }^{2}$, P. Roumeguere ${ }^{14}$, L. Siproudhis ${ }^{7}$, G. Staumont ${ }^{15}$, JD. Zeitoun ${ }^{16}$, Ph. Marteau ${ }^{17}$

\section{Correspondence to:}

Philippe Marteau, Pole Digestif, Hôpital Saint Antoine, 184 rue du faubourg Saint Antoine 75012 Paris, France.

Tel 33149282382

Electronic address: philippe.marteau@aphp.fr

\section{Author affiliations:}

${ }^{1}$ Department of Digestive Diseases, CHU Louis Mourier, AP-HP, 92700 Colombes, France

${ }^{2}$ Department of Proctology, Groupe Hospitalier Paris Saint Joseph, Institut Léopold Bellan, Paris, France.

${ }^{3}$ Department of Proctology and Digestive Diseases, CHU Bichat, AP-HP, Paris, France.

${ }^{4}$ Department of Digestive Diseases, Clinique des Cèdres, 31700 Cornebarrieu, France.

${ }^{5}$ Department of Proctology, Clinique Beau Soleil, 34070 Montpellier, France.

${ }^{6}$ Department of Proctology, Hôpital Bagatelle, 33401 Talence, France.

${ }^{7}$ Department of Digestive Diseases, CHU Pontchaillou, Rennes, France.

${ }^{8}$ Department of Digestive Diseases and Proctology, Polyclinique de Courlancy, 51100 Reims, France

${ }^{9}$ Department of Proctology, Clinique Clementville, 34070 Montpellier, France

${ }^{10}$ Department of Proctology, Clinique St Antoine, 06004 Nice, France.

${ }^{11}$ Department of Proctology, 59280 Armentieres, France.

${ }^{12}$ Department of Proctology, 94120 Fontenay-sous-Bois, France.

${ }^{13}$ Department of Proctology, Clinique Saint Augustin, 44000 Nantes, France.

${ }^{14}$ Department of Proctology, Clinique Tivoli, 33000 Bordeaux, France.

${ }^{15}$ Department of Proctology, Clinique St Jean Languedoc, 31400 Toulouse, France.

${ }^{16}$ Department of Digestive Diseases and Proctology, CHU Saint Antoine, AP-HP, 75012 Paris, France.

17 Philippe Marteau, Université Paris Sorbonne \& AP-HP, Pôle Digestif, Hôpital Saint Antoine 75012 Paris, France. 
Introduction

Anopernieal lesions are frequent during Crohn's disease (APLOC), heterogeneous and their presence and nature influence the prognosis and treatment strategies. ${ }^{1-5}$ Definitions of lesions, classifications and scores have been established. ${ }^{4-8}$ They must be known to specialists and be subject to initial and continuous training. We previously showed that ulceration, fistulae, inflammatory external openings of fistulae, erythema and abscess obtained an acceptable interobserver agreement between specialists. ${ }^{8}$ During their training, future gastroenterologists have to learn how to diagnose those lesions and their diagnostic skills have to reach the level of specialists.

The use of photographic, film and e-learning media is becoming increasingly important in education and has proved its effectiveness in several areas. ${ }^{9,10}$

The main objective of our study was to evaluate if an e-learning training with iconographic support was more efficient than an identical training but without image, for the diagnosis of APLOC by trainees in gastroenterology. The secondary objectives were to identify whether some lesions were more easily diagnosed after training with photos, and whether the trainings allowed students to achieve learning outcomes i.e. an acceptable level of APLOC diagnosis compared to senior experts.

Material and methods

A randomized controlled, open and national study was conducted. It was approved by the Group of Ethics and Medical Research of the Paris Saint Joseph Hospital Group.

The coordinating group (PhM, CG, VdP) selected the test and training photos, elaborated the evaluation grids for diagnostic skills, analyzed results and did not participate to the votes. The 19 other experts who belong to the Groupe de Recherche En Proctologie (GREP of the French National Society of Coloproctology) answered test 2 but were not involved in teaching and did not receive the teaching material.

Training in gastroenterology specialty in France lasts 4 years. The coordinating group contacted all gastroenterology trainees in France by e-mail and these tacitly agreed to participate in this study by answering the questionnaires. They were asked to answer a first questionnaire in which they had to make a diagnosis for 12 photos of APLOC using a closed answer form (Figure 1). Those who responded within one month were randomly assigned to two groups that received different e-learning training consisting of a one page document sent by email with unlimited availability. Group A received the APLOC definitions ${ }^{13}$ and typical photos (Figure 2). Group B received the APLOC definitions only (without the photos). One week after receiving this training material, the students received a second test in which they had to diagnose 12 new photos, different from the first (except for one photo).

A scoring grid with weighting of the main diagnoses was established by the coordinating group for each photo. Test 1 was scored on 167 points (figure 4), test 2 on 195 points and results were expressed as percentages of diagnosis fitting that of the coordinating group.

\section{Endpoints}

The primary endpoint of the study was the comparison of the results of test 2 between groups $\mathrm{A}$ and $\mathrm{B}$. The secondary endpoints were the comparison of diagnosis rates of ulceration, anal fistula, erythema, abscess and scrapie between groups $\mathrm{A}$ and $\mathrm{B}$, and between trainees and senior experts.

\section{Statistics}


Data were anonymized. The questionnaires were available via Google Drive allowing the automatic entry of results into a Microsoft Excel $^{\circledR}$ database. The randomization list was established by the random function of Excel ${ }^{\circledR}$. Statistical analyzes were performed using Excel $^{\circledR} 2013$ and SAS ${ }^{\circledR}$ softwares. For each test, a total score was assigned to each trainee. Comparisons of the means were carried out with a Student's test. The comparison of the percentages of exact lesion diagnosis was carried out by a $\mathrm{Chi}^{2}$ test. The comparison of the test score 2 between the experts and the trainees was done with a Wilcoxon test because the number of experts, less than 30 , did not correspond to a normal distribution. The comparison of lesion detection rates between experts and trainees was done using a Fisher test.

Results

The study flowchart is shown in figure 3. Two hundred and forty eight of the 465 trainees of gastroenterology in France answered test 1 (53.3\%), then were randomly divided into 2 groups ; 97 trainees from group A and 98 students from group B answered the second questionnaire (21.8\% and $21 \%$ lost to follow-up). The characteristics of the students, and results of test 1 in each group are shown in Table 1; there was no stastically significant difference between the two groups.

The diagnostic score for test 2 was $71.9 \% \pm 6.9(95 \%$ CI $[70.5 ; 73.3])$ versus $71.9 \% \pm 7.1$ $(95 \%$ CI $[70,73.3])$ for group A and B respectively $(\mathrm{p}=0.97)$ and $74.6 \% \pm 4.3(95 \% \mathrm{CI}$ $[72.1 ; 77.1]$ ) for the group of experts (p values 0.21 and 0.20 vs group A and B respectively). The detection rate of each elemental lesion of trainees and experts during test 2 are shown in Table 2. 
Discussion

Assessing teaching effectiveness is now felt as a priority to improve it. The diagnosis of APLOC is often thought to be difficult and requiring proper teaching. Consensual definitions of the lesions have been established. ${ }^{8}$ In this study, the addition of typical photos to a training material did not allow trainees to better diagnose APLOC at the inspection and the students trained with or without photos reached the learning outcome.

More than $50 \%$ of the total number of trainees in gastroenterology in France participated in our study. It is possible that some of the trainees who did not answer the questionnaires felt that they did not have enough skills to describe the APLOC; indeed the percentage of those in the first year of training was lower than that of those in the $2^{\text {nd }}$ and $3^{\text {rd }}$ year. Trainees in the $4^{\text {th }}$ year also had a lower percentage of response which may be explained by specialization in hepatology, oncology or endoscopy. The hypotheses explaining the $21 \%$ lost of follow up after completion of test 1 can be due to a lack of interest for the study, the time constraints and accessibility to the test. The orginising group did its best to limit the last 2 hypothesis.

The lack of difference of teaching effectiveness when pictures were added is contra-intuitive. It may be related to the equal quality of the two formations or to a lack of discrimination of our evaluation test. We decided not to give the same questionnaires for test 1 and 2 . The 12 photos of each test were chosen by the organizing group with in order to propose a short questionnaire, carried out in 10-15 minutes to obtain a high participation rate, have pictures representative of the different APLOC, and address a wide range of diagnostic difficulty. This can explain the score of only $75 \%$ obtained by the experts. Overall, after teaching, the differences in interpretation were not different between trainees and experts. The presence of one or two setons on some photos has undoubtedly helped in the diagnosis of fistula. But these photos allowed to evaluate the description of the characteristics of the fistulas (for example recognizing some complex fistulae). The scoring grid was established by the organizing group; it weighted the main diagnoses and provided points for negative diagnoses (for example diagnosing the absence of ulceration on a photo added 1 point to the score). The experts obtained a score not significantly higher than that of the students trained by the two methods. By analyzing item-by-item responses and calculating the detection rate of each lesion, numerous discrepancies were observed between the experts. For example, for erythema, the detection rate by the experts was $34 \% \pm 30$, which means that almost $2 / 3$ of the erythema labeled as such in the scoring grid by the 3 organizers, were not for the experts. This confirms previous studies with this variable, which also has a poor reproducibility in endoscopic scores. ${ }^{8,11-13}$ Our study design would have been improved if we had planed independence between the experts who provide the teaching and those who evaluate it by test and grids. Finally, the lack of difference between the two types of training may also reveal the limitations of APLOC diagnosis at the inspection as indicated by expert. Indeed, palpation and often MRI are required to properly diagnose stenosis and perforating lesions such as some fistulas, abscesses, and deep ulcers. ${ }^{4-6,8,14}$

Ano-perineal lesions of Crohn's disease are a diagnostic and therapeutic issue, and this was to our knowledge the first study evaluating web based teaching methods in this field. We conclude that the result of the present study showing no apparent benefit of adding photos to the training trainees should not be considered as definitive but that although trainees reached the level expected, better training methods can be developed and that evaluation of teaching should also progress. 


\section{Thanks}

The photo database was created from photographs by Drs. Manuel Aubert, Boubekeur Bennadji, Jean-François Contou, Elise Crochet, Nadia Fathallah, Philippe Marteau, Benoit Mory, Vincent de Parades, Elise Pommaret, Laurent Siproudhis and Ghislain Staumont, (in the majority, members of Research Group of Proctology, GREP).

Conflicts of interest: none 


\section{Online training for the diagnosis of anoperineal lesions of Crohn's disease: Do pictures matter? A nationwide randomised study}

\section{References}

1. Beaugerie L, Seksik P, Nion-Larmurier I, Gendre J-P, Cosnes J. Predictors of Crohn's disease. Gastroenterology 2006;130:650-6

2. Herman Y, Rinawi F, Rothschild B, Nir O, Shamir R, Assa A. The Characteristics and Long-term Outcomes of Pediatric Crohn's Disease Patients with Perianal Disease. Inflamm Bowel Dis 2017;23:1659-1665

3. Park Y, Cheon JH, Park YL, Ye BD, Kim YS, Han DS, Kim JS, Hong SN, Kim YH, Jeon SR, Kim WH; IBD Study Group of the Korean Association for the Study of Intestinal Diseases (KASID). Development of a Novel Predictive Model for the Clinical Course of Crohn's Disease: Results from the CONNECT Study. Inflamm Bowel Dis 2017 ;23:1071-1079

4. Gecse KB, Bemelman W, Kamm MA, Stoker J, Khanna R, Ng SC, Panés J, van Assche G, Liu Z, Hart A, Levesque BG, D'Haens G; World Gastroenterology Organization, International Organisation for Inflammatory Bowel Diseases IOIBD, European Society of Coloproctology and Robarts Clinical Trial. A global consensus on the classification, diagnosis and multidisciplinary treatment of perianal fistulising Crohn's disease. Gut 2014;63:1381-92.

5. Sandborn WJ, Fazio VW, Feagan BG, Hanauer SB, American Gastroenterological Association Clinical Practice Committee. AGA technical review on perianal Crohn's disease. Gastroenterology 2003;125:1508-30

6. Anoperineal Lesions in Crohn's Disease : French Recommandations for Clinical Practise. D Bouchard et al. Tech Coloproctol 21 (9), 683-691. 2017 Sep 19

7. Hughes LE. Clinical classification of perianal Crohn's disease. Dis Colon Rectum. 1992;35:928-32

8. Irvine EJ. Usual therapy improves perianal Crohn's disease as measured by a new disease activity index. McMaster IBD Study Group. J Clin Gastroenterol 1995;20:2732

9. Horaist C, de Parades V, Abramowitz L, Benfredj P, Bonnaud G, Bouchard D, Fathallah N, Sénéjoux A, Siproudhis L, Staumont G, Viguier M, Marteau P. Elaboration and validation of Crohn's disease anoperineal lesions consensual definitions. World J Gastroenterol 2017;23:5371-5378

10. Adar T. E-learning in gastroenterology-What have we learned so far? United European Gastroenterol J 2017;5:603-604

11. Nakanishi H, Doyama H, Ishikawa H, Uedo N, Gotoda T, Kato M, et al. Evaluation of an e-learning system for diagnosis of gastric lesions using magnifying narrow-band imaging: a multicenter randomized controlled study. Endoscopy 2017;49:957-967 
12. Spanos CP, Tsapas A, Abatzis-Papadopoulos M, Theodorakou E, Marakis GN. Medical student recognition of benign anorectal conditions: the effect of attending the outpatient colorectal clinic. BMC Surg 2014;14:95.

13. Travis SPL, Schnell D, Krzeski P, Abreu MT, Altman DG, Colombel J-F, Feagan BG, Hanauer SB, Lémann M, Lichtenstein GR, Marteau PR, Reinisch W, Sands BE, Yacyshyn BR, Bernhardt CA, Mary JY, Sandborn WJ. Developing an instrument to assess the endoscopic severity of ulcerative colitis: the Ulcerative Colitis Endoscopic Index of Severity (UCEIS). Gut 2012;61:535-42

14. Travis SPL, Schnell D, Krzeski P, Abreu MT, Altman DG, Colombel J-F, Feagan BG, Hanauer SB, Lichtenstein GR, Marteau PR, Reinisch W, Sands BE, Yacyshyn BR,Schnell P, Bernhardt CA, Mary JY, Sandborn WJ. Reliability and initial validation of the ulcerative colitis endoscopic index of severity. Gastroenterology. 2013;145:987-95

15. Panés J, Rimola J. Perianal fistulizing Crohn's disease: pathogenesis, diagnosis and therapy. Nat Rev Gastroenterol Hepatol 2017;14:652-664 
Figure 1. Standardized answer form for each photo (for tests 1 and 2)

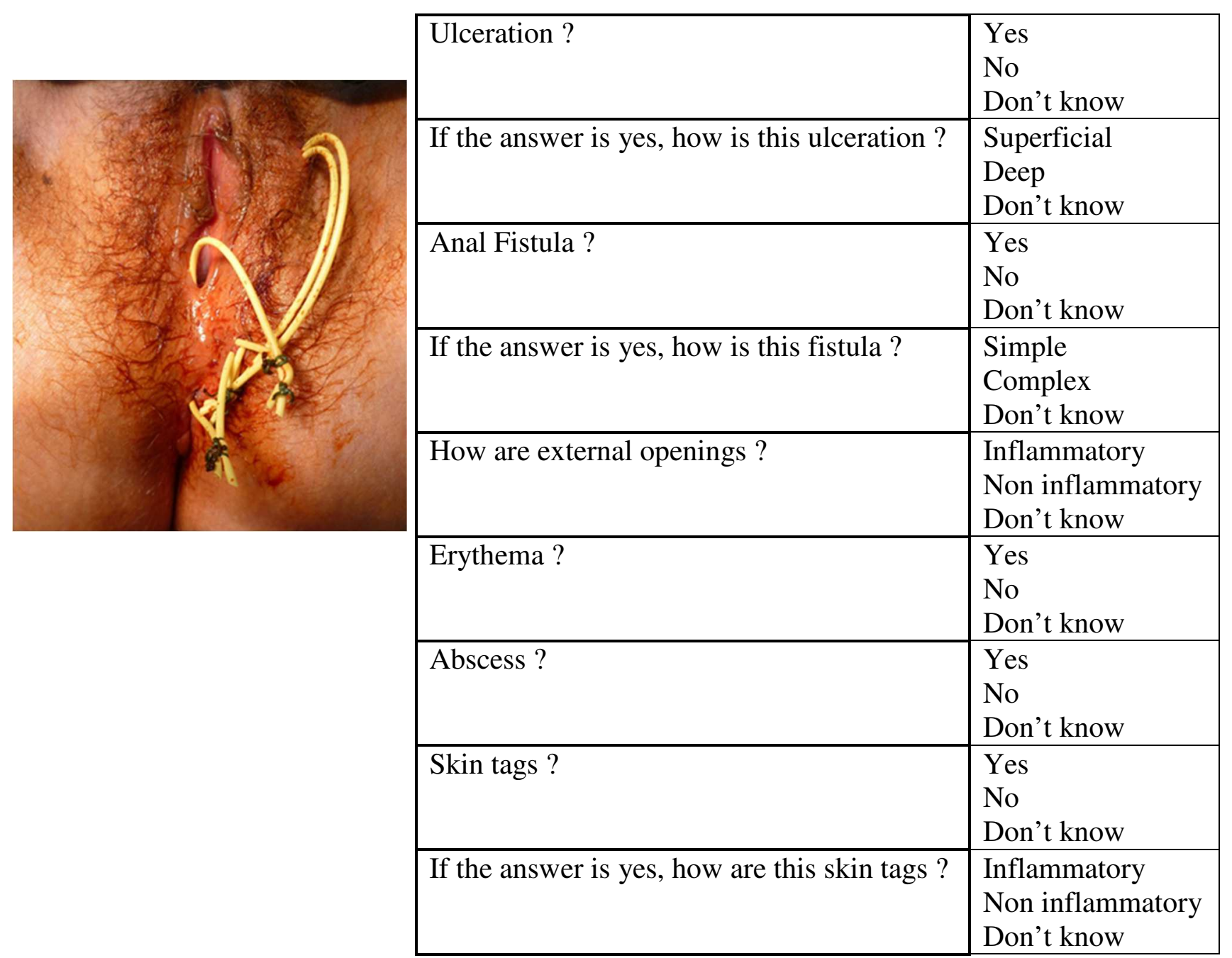


Figure 2. Web-based teaching material in group A : consensual and validated definitions of APLOC 13 and photos illustrating the typical aspects of each lesion (group B received the definitions but not these photos)

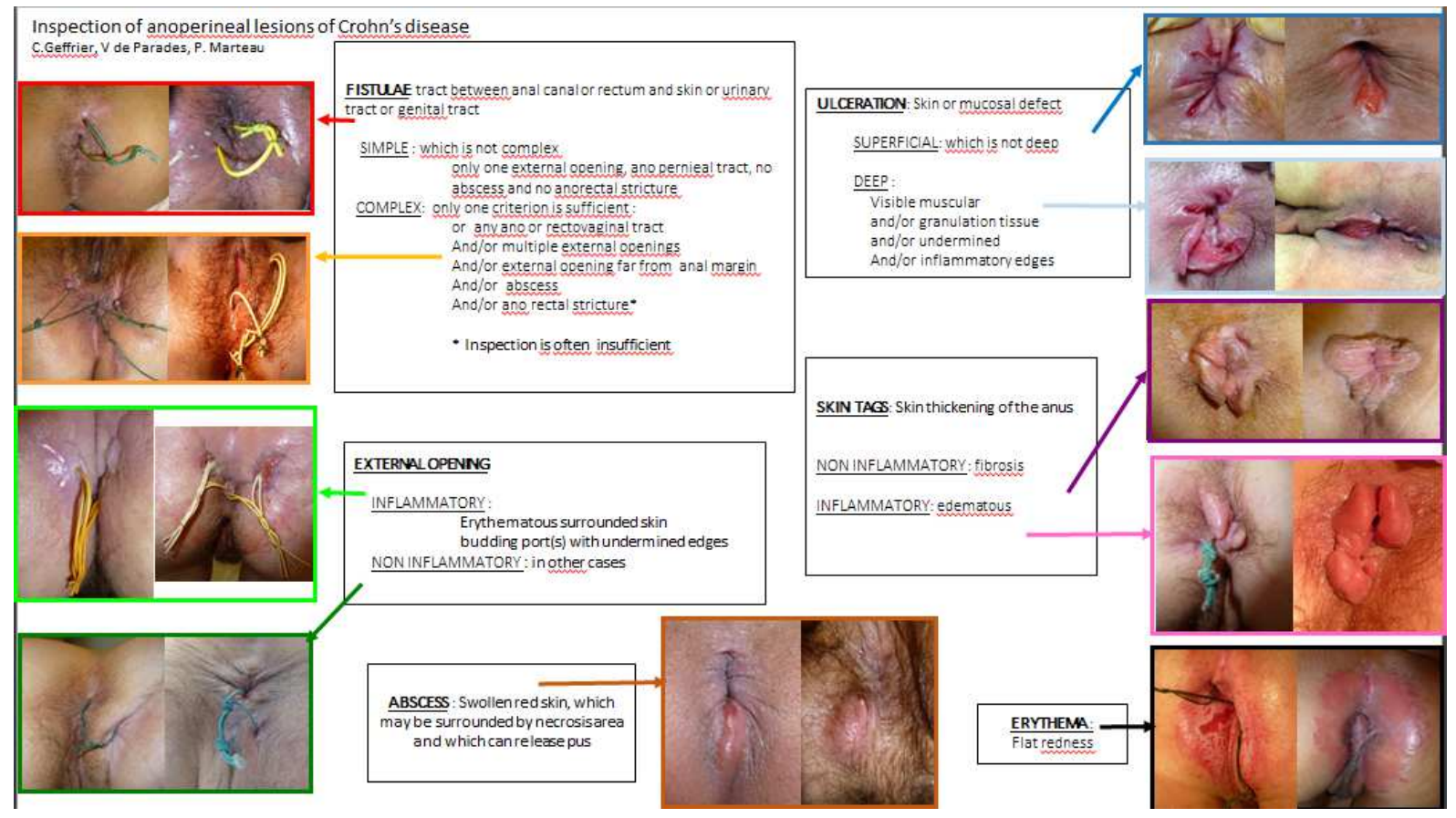


Figure 3 : Study flow chart

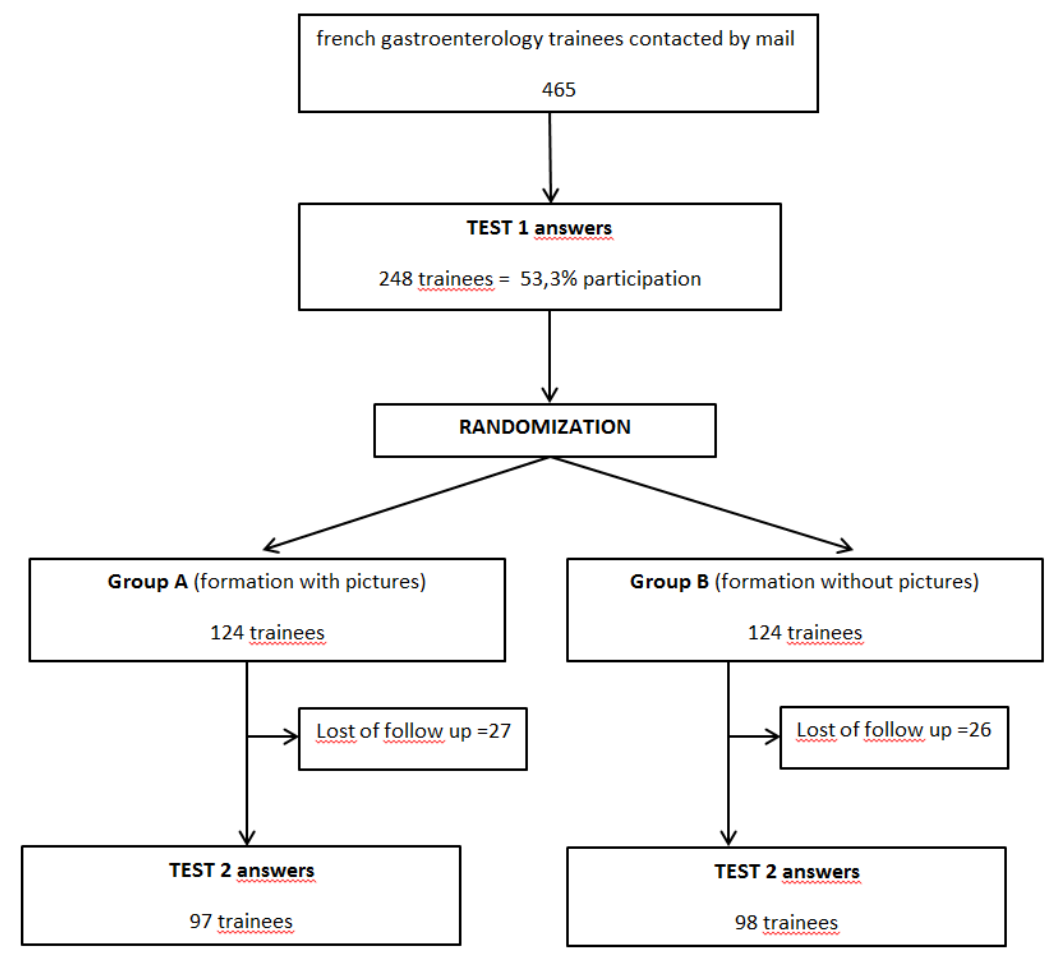


Table 1. Characteristics of the trainees

\begin{tabular}{|l|l|c|c|}
\hline \multicolumn{2}{|c|}{} & $\begin{array}{c}\text { Group A } \\
\left(\mathrm{N}=\mathbf{1 2 1}^{*}\right)\end{array}$ & $\begin{array}{c}\text { Group B } \\
(\mathrm{N}=\mathbf{1 1 7})\end{array}$ \\
\hline \multirow{3}{*}{ Training year } & 1 st & $\mathbf{2 1}(17.4)$ & $\mathbf{1 7}(14.5)$ \\
\cline { 2 - 4 } & $2^{\text {nd }}$ & $\mathbf{2 5}(20.7)$ & $\mathbf{3 4}(29.1)$ \\
\cline { 2 - 4 } & $3^{\text {rd }}$ & $\mathbf{4 5}(37.2)$ & $\mathbf{3 2}(27.3)$ \\
\cline { 2 - 4 } & $4^{\text {th }}$ & $\mathbf{3 0}(24.8)$ & $\mathbf{3 4}(29.1)$ \\
\hline \multicolumn{2}{|l|}{ Diagnostic score at test 1 (\%) } & $\mathbf{7 6 . 6} \pm 6.2$ & $\mathbf{7 5 . 9} \pm 6.2$ \\
\multicolumn{2}{|l|}{} & IC95\% $[75.5 ; 77.7]$ & IC95\% $[74.8 ; 77.0]$ \\
\hline
\end{tabular}

* Missing data for 10 patients who participated in the test 1 . 
Table 2. Diagnostic scores for test 2

* number of lesions of each type present in test 2 according to the organizing group

$\ddagger \mathbf{p} 1=$ comparison of group $\mathrm{A}$ and experts

$\S \mathrm{p} 2=$ comparison of group $\mathrm{B}$ and experts

$\| \mathrm{p} 3=$ comparison of group A and B

\begin{tabular}{|l|c|c|c|c|c|c|c|}
\hline Test 2 & $\mathbf{N}^{*}$ & $\begin{array}{c}\text { Experts } \\
\mathrm{N}=14\end{array}$ & $\mathbf{p} 1 \neq$ & $\begin{array}{c}\text { Group A } \\
\mathrm{N}=97\end{array}$ & $\mathbf{p} 2 \S$ & $\begin{array}{c}\text { Group B } \\
\mathrm{N}=98\end{array}$ & $\mathbf{p 3 \|}$ \\
\hline Abcess & 1 & 100 & 0.11 & 100 & 0.18 & 100 & 0.84 \\
\hline Ulceration & 6 & $97.6 \pm 5.8$ & 0.69 & $72.0 \pm 32.3$ & 0.69 & $72.9 \pm 31.2$ & 0.82 \\
\hline Fistula & 9 & $92.1 \pm 19.1$ & 0.58 & $85.2 \pm 30.6$ & 0.17 & $85.8 \pm 29.8$ & 0.80 \\
\hline Skin tags & 10 & $75.7 \pm 31.6$ & 0.54 & $67.5 \pm 24.8$ & 0.54 & $65.6 \pm 20$ & 0.10 \\
\hline Erythema & 10 & $34.3 \pm 29.9$ & & $44.1 \pm 21.7$ & & $55.6 \pm 20.8$ & \\
\hline
\end{tabular}

